Original Research Article

\title{
Effect of ranolazine on HbA1c and blood glucose levels in diabetic patients with chronic angina
}

\author{
Shilpa B. N. ${ }^{1}$, Shashikala G. H. ${ }^{1 *}$, Siddesh ${ }^{2}$, Mallesh P. ${ }^{3}$
}

${ }^{1}$ Department of Pharmacology, JJMMC, Davangere, Karnataka, India

${ }^{2}$ Department of Medical

Gastroenterology, MIOT

Hospital, Chennai, Tamilnadu,

India

${ }^{3}$ Consultant Cardiologist, Bapuji

Hospital, JJMMC, Davangere,

Karnataka, India

Received: 09 January 2019

Accepted: 04 February 2019

*Correspondence to:

Dr. Shashikala G. H.,

Email: shashikalagh28@

gmail.com

Copyright: () the author(s), publisher and licensee Medip Academy. This is an openaccess article distributed under the terms of the Creative Commons Attribution NonCommercial License, which permits unrestricted noncommercial use, distribution, and reproduction in any medium, provided the original work is properly cited.

\begin{abstract}
Background: Diabetes mellitus is the fifth leading cause of death worldwide and is one of the common co-morbid conditions associated with coronary artery disease (CAD). The overall prevalence of CAD is $7.4 \%$ but the prevalence of $\mathrm{CAD}$ in diabetics is $9 \%$. Hence treatment of hyperglycemia is a key goal of secondary preventive therapy with a target of reducing $\mathrm{HbA} 1 \mathrm{c}$ to $<7 \%$. The risk of $\mathrm{CAD}$ has been reported to occur 2 to 3 decades prior in diabetics compared to non-diabetics. Hence discovery of drugs with potential role in both diabetes and CAD seems to be necessary. Ranolazine is a novel oral anti anginal drug known to reduce HbA1c and fasting blood glucose levels in angina patients with diabetes. The objective of this study is to show the effect of ranolazine (antianginal drug) on $\mathrm{HbA} 1 \mathrm{c}$ and fasting blood glucose levels in diabetic patients with chronic angina.

Methods: Patients were divided into: Group 1 continued with previous antidiabetic drugs and antianginal drugs. Group 2 were prescribed Tab ranolazine $1000 \mathrm{mg}$ b.d (orally) as add on therapy along with previous antidiabetic drugs and antianginal drugs.

Results: There was a significant reduction in HbA1c and FBS levels in Group 2 patients who were on ranolazine. Reduction of HbA1c in group1 and Group 2 was $0.21 \pm 0.65 \%$ and $1.30 \pm 1.16 \%$ respectively. Reduction of FBS in group1 and group2 was $10.66 \pm 27.80 \mathrm{mg} / \mathrm{dl}$ and $29.97 \pm 31.49 \mathrm{mg} / \mathrm{dl}$ respectively.

Conclusions: From the present study we can conclude that ranolazine, an antianginal drug when given at a dose of $1000 \mathrm{mg}$ bd in diabetic patients with chronic angina reduces HbA1c and FBS levels.
\end{abstract}

Keywords: CAD, Diabetes mellitus, FBS, HbA1c, Ranolazine

\section{INTRODUCTION}

Diabetes poses a major health problem globally and is one of the top five leading causes of death in most developed countries.

A substantial body of evidence suggests that it could reach epidemic proportions particularly in developing and newly industrialized countries. Coronary artery disease (CAD is one of the common co-morbid conditions associated with diabetes. ${ }^{1}$ Diabetes is an established risk factor for cardiovascular disease and risk increases with worsening hyperglycemia. ${ }^{2}$

Prevalence of CAD risk factors among diabetics is $63 \%$ and non-diabetics is $51 \%{ }^{3}$ The overall prevalence of CAD is $7.4 \%$ but the prevalence of CAD in diabetics is $9 \% .^{4,5}$

Risk of CAD was reduced by $20 \%$ in patients with a mean HbA1c of $6.5 \%$ compared to those with a mean level of $7.5 \%$. Hence treatment of hyperglycemia is a key goal of secondary preventive therapy with a target of reducing 
HbA1c to $<7 \%{ }^{6,7}$ The risk of CAD has been reported to occur 2 to 3 decades prior in diabetics compared to nondiabetics. Hence discovery of drugs with potential role in both diabetes and CAD is necessary. ${ }^{8}$ Ranolazine is a novel hemodynamically neutral antianginal and anti ischemic compound with cardioprotective properties and can be used both as monotherapy and as add on therapy when symptoms are not relieved with other antianginal drugs. ${ }^{9}$

It was approved by FDA as an antianginal drug in 2006, but post hoc analyses of various angina trials suggested the drug might be effective in diabetic patients, not only for its role in eliminating angina but also for its ability to lower HbA1c levels. ${ }^{10}$

Previous studies have shown that ranolazine $1000 \mathrm{mg}$ b.d in patients with diabetes and chronic angina can reduce HbA1c and FBS Levels. ${ }^{11}$

The aim of this study is to show the effect of ranolazine (anti anginal drug) on HbA1c and blood glucose levels when given in diabetic patients with chronic angina at a dose of $1000 \mathrm{mg}$ b.d (orally) for a period of 12 weeks in Indian population. Objective of this study is to evaluate the effect of ranolazine on HbA1c and FBS levels in patients of diabetes mellitus with chronic angina.

\section{METHODS}

This was open labelled prospective study. This study was conducted in the Department of Pharmacology, JJM Medical College, Davangere. This clinical study was conducted in patients suffering from diabetes with chronic angina, attending cardiology department, Bapuji hospital, Davangere. This study was conducted for period of 18 months.

\section{Inclusion criteria}

- $\quad$ Either gender, aged $\geq 18$ years,

- Patients with chronic angina of $>3$ months,

- Patients with diabetes mellitus (HbA1c level >7\% and FBS $>140 \mathrm{mg} / \mathrm{dl}$ ).

\section{Exclusion criteria}

- Renal failure,

- Chronic lung disease,

- H/o valvular heart disease,

- Hepatic failure,

- Patient on CYP3A4 inducers or CYP3A4 inhibitors

- $\quad$ Patients on drugs known to prolong QT interval e.g. quinidine, procainamide, chlorpromazine etc.

- Pregnancy or absence of contraceptive use in women of child bearing age/ lactating mother.

A minimum of 62 patients fulfilling the inclusion criteria and who have given written consent were selected and divided into two groups:
Group 1: Patients in this group continued with previous antidiabetic drugs (sulfonylureas, metformin, insulin etc.) and antianginal drugs without ranolazine.

Group 2: Patients with inadequate control of angina symptoms were prescribed ranolazine $1000 \mathrm{mg}$ b.d as add on therapy along with current antidiabetic drugs (metformin, sulfonylureas, insulin etc.) and antianginal drugs.

All patients followed diabetic diet as recommended by physician. The following baseline parameters were recorded and repeated after 3 months. The parameters are:

- HbA1c (glycated hemoglobin),

- FBS.

Demographic details were also collected. Qualitative data was represented in the form of frequency and percentage. Association of variables was done with Chi Square Test and Fisher's exact test for 2 × 2 tables where $P$ value of chi square test was not valid due to small counts.

Quantitative data was represented in the form of mean and standard deviation. Comparison of mean within the group was done using paired t test. Mean difference between the two groups was done using unpaired t test and by MannWhitney U test if the data fails Normality test. Statistical analysis done using IBM SPSS Version 20 for Windows.

\section{RESULTS}

All the baseline parameters were comparable in both the groups except for frequency of angina (Table 1).

In group 1 patients, there is a reduction of $\mathrm{HbA} 1 \mathrm{c}$ levels from baseline to after 3 months with a p-value of 0.09 which is statistically not significant. There is also a reduction of FBS from baseline to after 3 months with a pvalue $<0.04$ which is statistically significant (Table 2 and Figure 1).

In group 2 patients, there is a reduction of $\mathrm{HbA} 1 \mathrm{c}$ levels from baseline to after 3 months with a p-value of $\mathrm{p}<0.001$ which is statistically highly significant. There is an also reduction of FBS from baseline to after 3 months with a pvalue $<0.001$ which is statistically highly significant (Table 3 and Figure 2).

When intergroup comparison is done for mean reduction in HbA1c between group 1 and group 2, the results are statistically highly significant with p-value $<0.001$ showing that ranolazine has HbAlc reducing property. When intergroup comparison is done for mean reduction in FBS between group 1 and group 2, the results are statistically significant with p-value $=0.010$ (Table 4 and Figure 3, Figure 4). 
Table 1: Patient demographic details.

\begin{tabular}{|c|c|c|c|c|c|}
\hline Sr. No & \multicolumn{2}{|c|}{ Baseline characteristics } & Group 1 & Group 2 & p value \\
\hline 1 & \multicolumn{2}{|c|}{ Age (yrs) } & 60.39 & 58.06 & \\
\hline \multirow[b]{2}{*}{2} & \multirow{2}{*}{ Sex } & Male & 19 & 21 & \multirow{2}{*}{$0.282, \mathrm{NS}$} \\
\hline & & Female & 12 & 10 & \\
\hline 3 & \multicolumn{2}{|c|}{ Duration of DM (Years) } & $6.45 \pm 4.84$ & $6.03 \pm 3.66$ & $0.702, \mathrm{NS}$ \\
\hline 4 & \multicolumn{2}{|c|}{ Duration of CAD (Years) } & $3.13 \pm 2.38$ & $3.13 \pm 2.36$ & $1.0, \mathrm{NS}$ \\
\hline 5 & \multicolumn{2}{|c|}{ HbA1c $(\%)$} & $9.54 \pm 1.81$ & $10.33 \pm 1.49$ & $0.065, \mathrm{NS}$ \\
\hline 6 & \multicolumn{2}{|l|}{ FBS (mg/dl) } & $220.79 \pm 67.34$ & $208.79 \pm 47.61$ & $0.427, \mathrm{NS}$ \\
\hline \multirow{4}{*}{7} & \multirow{4}{*}{$\begin{array}{l}\text { Frequency of } \\
\text { angina/week }\end{array}$} & 0 & 13 & 6 & \multirow{4}{*}{0.02} \\
\hline & & $<1$ & 6 & 0 & \\
\hline & & $1-2$ & 11 & 19 & \\
\hline & & 3- 4 & 1 & 6 & \\
\hline \multicolumn{5}{|c|}{ Concomitant drugs } & \\
\hline \multicolumn{5}{|c|}{ Antidiabetic drugs N (\%) } & \\
\hline & \multicolumn{2}{|l|}{ Sulfonylurea } & $20(64.5)$ & $22(71)$ & \\
\hline & \multicolumn{2}{|l|}{ Metformin } & $21(67.7)$ & $22(71)$ & \\
\hline & \multicolumn{2}{|c|}{ Insulin } & $9(29.0)$ & $10(32.3)$ & \\
\hline & \multicolumn{2}{|c|}{ Thiazolidinediones } & $4(12.9)$ & $3(9.7)$ & \\
\hline & \multicolumn{2}{|c|}{$\alpha$ Glucosidase inhibitors } & $1(3.2)$ & $3(9.7)$ & \\
\hline \multicolumn{5}{|c|}{ Antianginal and other drugs } & \\
\hline & \multicolumn{2}{|l|}{ Aspirin } & $29(93.5)$ & $27(87.1)$ & \\
\hline & \multicolumn{2}{|l|}{ Clopidogrel } & $20(64.5)$ & $22(71)$ & \\
\hline & \multicolumn{2}{|c|}{ Statins } & $29(93.5)$ & $28(90.3)$ & \\
\hline & \multicolumn{2}{|c|}{ Isosorbide mononitrate } & $7(22.6)$ & $10(32.3)$ & \\
\hline & \multicolumn{2}{|c|}{ Isosorbide dinitrate } & $8(25.8)$ & $8(25.8)$ & \\
\hline & \multicolumn{2}{|c|}{ B blocker } & $8(25.8)$ & $5(16.1)$ & \\
\hline & \multicolumn{2}{|c|}{ Calcium channel blocker } & $1(3.2)$ & 0 & \\
\hline
\end{tabular}

Table 2: HbA1c and FBS in group 1 patients (baseline and after 3 months).

\begin{tabular}{|cllll|}
\hline Clinical Variables & \multicolumn{2}{|l|}{ Group-1 Without ranolazine $(\mathbf{N}=\mathbf{3 1})$} & \multicolumn{3}{c|}{ Paired t Test } \\
& Before Mean \pm SD & After 3 Months Mean \pm SD & t Value & p Value \\
\hline HbA1c \% & $9.54 \pm 1.81$ & $9.33 \pm 1.66$ & 1.749 & 0.09, NS \\
\hline FBS mg/dl & $220.79 \pm 67.34$ & $210.13 \pm 55.02$ & 2.136 & $<0.04 *$ \\
\hline *significant $(\mathrm{p}<0.05)$ & & & &
\end{tabular}

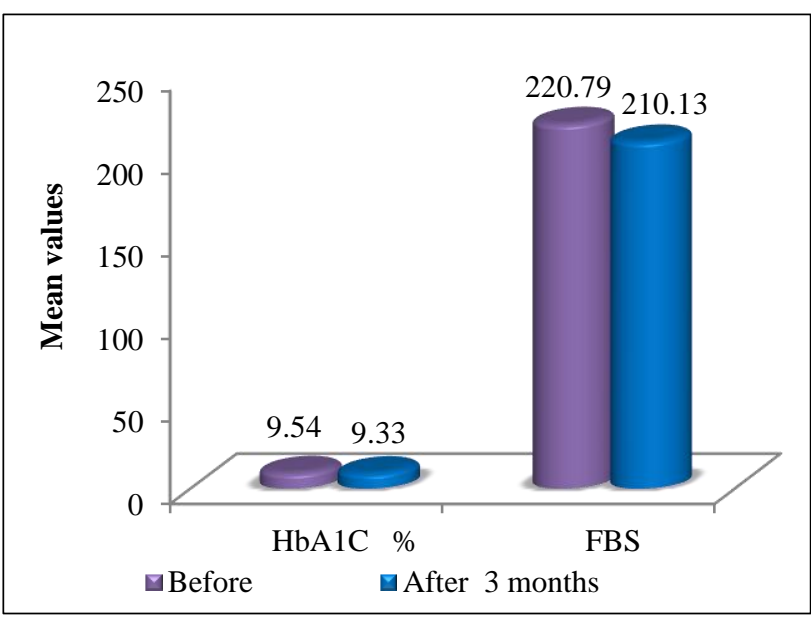

Figure 1: HbA1c and FBS in group 1 patients (baseline and after 3 months).

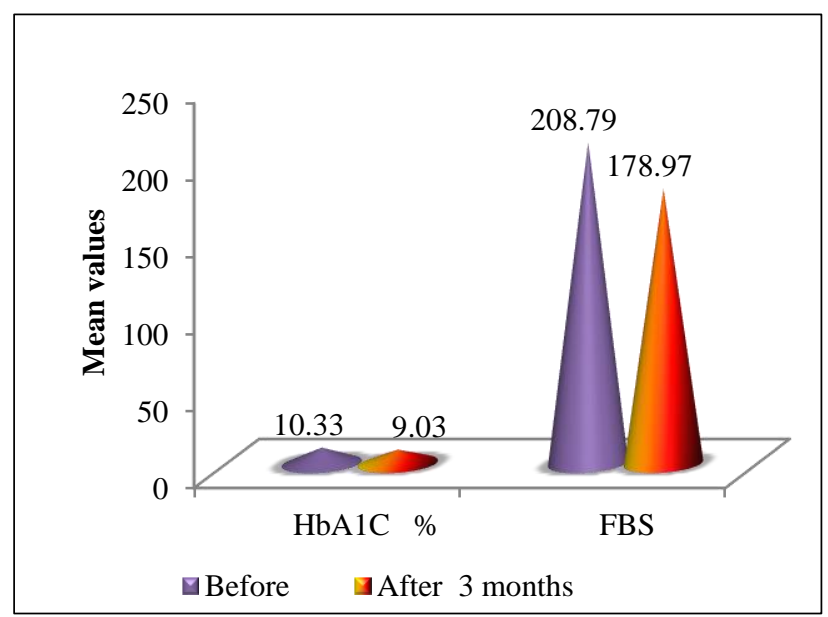

Figure 2: HbA1c and FBS in group 2 patients (baseline and after 3 months). 
Table 3: Hba1c and FBS in group 2 patients (baseline and after 3 months).

\begin{tabular}{|c|c|c|c|c|}
\hline \multirow{2}{*}{ Clinical Variables } & \multicolumn{2}{|c|}{ Group-2 With Ranolazine (N=31) } & \multicolumn{2}{|c|}{ Paired t Test } \\
\hline & Before Mean \pm SD & After Mean \pm SD & t Value & $\mathrm{p}$ Value \\
\hline $\mathrm{HbA1c} \%$ & $10.33 \pm 1.49$ & $9.03 \pm 1.03$ & 6.257 & $<0.000 * *$ \\
\hline FBS mg/dl & $208.79 \pm 47.61$ & $178.97 \pm 26.8$ & 5.297 & $<0.000 * *$ \\
\hline
\end{tabular}

Table 4: Comparison of Hba1c and FBS between group 1 and group 2.

\begin{tabular}{|c|c|c|c|c|c|}
\hline \multirow{2}{*}{\multicolumn{2}{|c|}{ Clinical Variables }} & \multirow{2}{*}{$\begin{array}{l}\text { Group-1 Without } \\
\text { ranolazine }(\mathrm{N}=31)\end{array}$} & \multirow{2}{*}{$\begin{array}{l}\text { Group-2 With } \\
\text { ranolazine }(\mathrm{N}=31)\end{array}$} & \multicolumn{2}{|c|}{ Unpaired t test } \\
\hline & & & & t value & p value \\
\hline \multirow{3}{*}{$\mathrm{HbA} 1 \mathrm{c} \%$} & Before: Mean \pm SD & $9.54 \pm 1.81$ & $10.33 \pm 1.49$ & & \\
\hline & After: Mean \pm SD & $9.33 \pm 1.66$ & $9.03 \pm 1.03$ & & \\
\hline & Mean difference between before \& after & $0.21 \pm 0.65$ & $1.30 \pm 1.16$ & 3.841 & $0.000 * *$ \\
\hline \multirow{3}{*}{ FBS } & Before: Mean \pm SD & $220.79 \pm 67.34$ & $208.79 \pm 47.61$ & & \\
\hline & After: Mean \pm SD & $210.13 \pm 55.02$ & $178.97 \pm 26.8$ & & \\
\hline & Mean difference between before \& after & $10.66 \pm 27.80$ & $29.97 \pm 31.49$ & 2.558 & $0.010 *$ \\
\hline
\end{tabular}

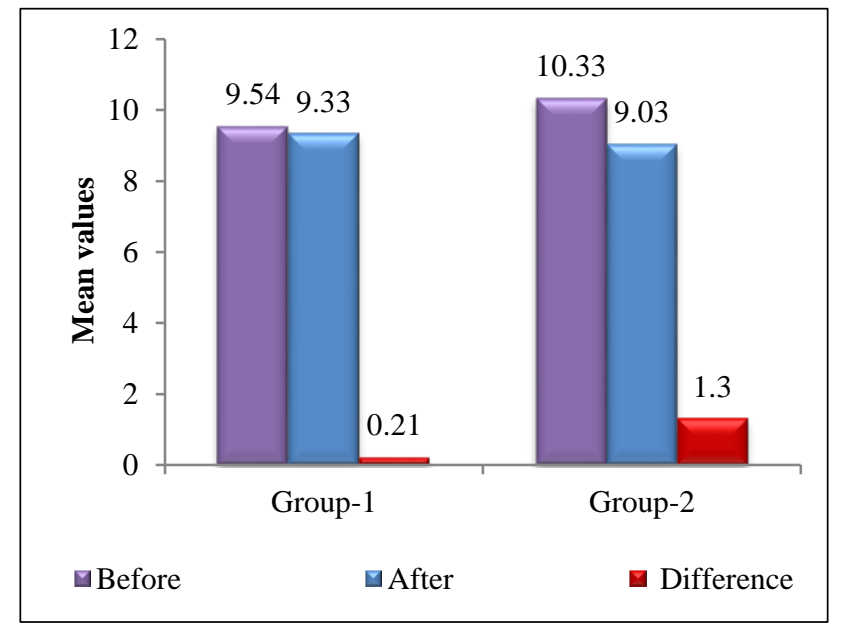

Figure 3: Comparison of Hba1c between group 1 and group 2.

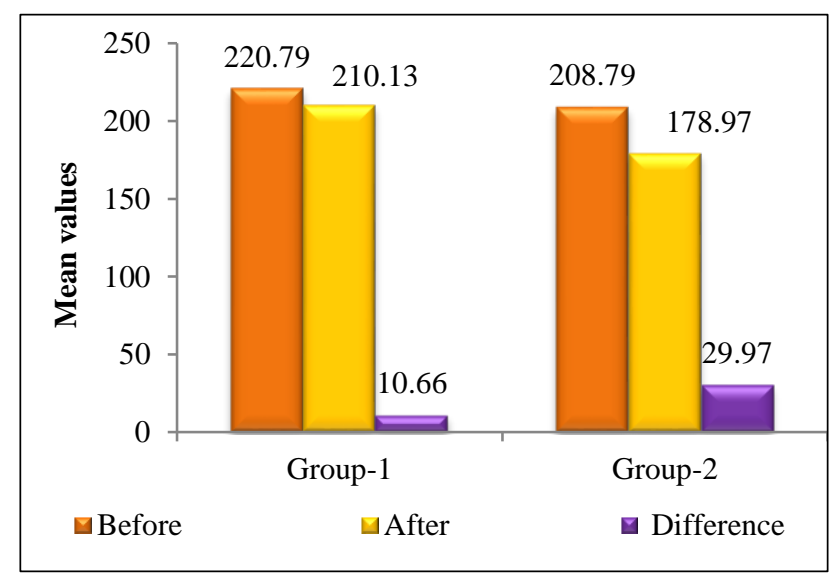

Figure 4: Comparison of FBS between group 1 and group 2.

\section{DISCUSSION}

CAD and DM are two distinct disease entities which are interlinked. Metabolic derangements in diabetes leads to increased risk for CAD.

Ranolazine is a novel oral anti anginal drug known to reduce $\mathrm{HbA1c}$ and fasting blood glucose levels in angina patients with diabetes. ${ }^{12}$ The present open labelled prospective study was conducted to assess the effect of ranolazine on $\mathrm{HbA} 1 \mathrm{c}$ and fasting blood sugar levels in patients of diabetes mellitus with chronic angina.

The baseline characteristics and concomitant medications were similar in both the groups, hence comparable which is similar to the study conducted by Selvarajan $\mathrm{S}$ et al where ranolazine is compared with trimetazidine to evaluate for the reduction in HbA1c levels. ${ }^{12}$ Patients in group 2 had increased frequency of angina per week compared to group 1. Ranolazine is indicated in patients with chronic angina who are inadequately controlled with first line antianginal drugs as an add on therapy therefore patients in group 2 received ranolazine as an add on drug (Table 1).

The type of antidiabetic drugs used for group 1 and group 2 patients with a history of diabetes was similar. The majority of patients were taking either metformin and/or sulfonylurea which is similar to the study conducted by Selvarajan $\mathrm{S}$ et al. ${ }^{12}$ There were no major changes in the antidiabetic drugs in both the groups between 0 and 3 months. Hence, the effect of ranolazine on FBS and HbA1c does not appear to be attributable to use of concurrent anti diabetic therapy in ranolazine-treated patients group 2 (Table 1). Both the groups have received similar antianginal and other drugs (Table 1). 
In group 1 , the mean reduction of $\mathrm{HbA} 1 \mathrm{c}$ in group 1 from baseline to 12 weeks was $0.21 \%$ which is not statistically significant with $\mathrm{p}$ value of 0.09 (Table 2 and Figure 1). This is similar to the study conducted by Timmis A et al where change in $\mathrm{HbA} 1 \mathrm{c}$ levels from baseline to 12 weeks was $0.02 \%$ which was also not statistically significant. ${ }^{11}$ However there was a statistically significant reduction of FBS with a p-value $<0.04$ (Table 2 and Figure 1).

In Group 2, the mean reduction in HbA1c level from baseline to 12 weeks was $1.3 \pm 0.46$ which is statistically highly significant with a p-value $<0.001$ (Table 3 and Figure 2) Results from our study is similar to the results from the study conducted by Timmis A et al where change in $\mathrm{HbA1c}$ levels from baseline to 12 weeks was $0.70 \pm 0.18 \%$ which is also statistically significant and also in a study by Chisholm JW et al ranolazine reduced $\mathrm{HbA1c}$ by $1.2 \%$ in 12 weeks. $^{11,10}$

Similarly reduction in group 2 FBS from baseline to 12 weeks was $29.97 \pm 20.81 \mathrm{mg} / \mathrm{dl}$ which is statistically highly significant with a p-value $<0.001$ (Table 3 and Figure 2). Same results are also reflected in a study conducted by Chisholm JW et al to evaluate the effect of ranolazine on HbA1c and blood glucose levels, where reduction in FBS was $25.7 \mathrm{mg} / \mathrm{dl} .^{10}$

When comparison is done for reduction in $\mathrm{HbAlc}$, the mean difference in the reduction of $\mathrm{HbA} 1 \mathrm{c}$ between group 2 and group 1 was found to be $1.09 \pm 0.5$. The results are statistically highly significant with p-value $<0.001$ showing HbA1c reducing property of ranolazine.

The mean difference in the reduction in FBS between group 2 and group 1 was $19.31 \pm 3.69$ which is also statistically significant with p-value $=0.010$ (Table 4, Figure 3 and Figure 4).

Similarly, results are seen in 2 studies conducted by Timmis A et al and Chisholm JW et al, where ranolazine was found to effective in reducing $\mathrm{HbA} 1 \mathrm{c}$ and blood glucose levels when compared to placebo. ${ }^{11,10}$

It was observed that the HbAlc lowering property of ranolazine was greater in patients with more marked hyperglycemia i.e. with HbA1c levels of $>9 \%$.

Though the magnitude of reduction of HbA1c levels by ranolazine appears small, it is important to note that this additional beneficial effect is from the drug which is already established to be an antianginal drug. No adverse effects were reported by patients taking ranolazine. Previous studies have shown that ranolazine $1000 \mathrm{mg}$ b.d in patients with diabetes and chronic angina can reduce HbA1c and FBS levels.

CARISA study done by Adam D Timmis, Bernard, Michael, dept of cardiology, London showed that Ranolazine significantly lowered HbA1c by $0.70 \pm 0.18 \%$ in patients with diabetes mellitus and chronic angina when given at a dose of $1000 \mathrm{mg}$ b.d for 12 weeks. The results of this study suggested that ranolazine may be an effective and well tolerated antianginal medication in diabetic patients with chronic angina. ${ }^{11}$

MERLIN-TIMI-36 study done by Jeffrey, Allison, Arvindu, Eugen demonstrated the effects of ranolazine on $\mathrm{HbA} 1 \mathrm{c}$ and glucose levels using prespecified glycemic end points followed at an interval of 4,8 and 16 months. This study showed that ranolazine $1000 \mathrm{mg}$ twice daily reduced HbAlc by $1.2 \%$ and FBS by $25.7 \mathrm{mg} / \mathrm{dl} .{ }^{10}$ In our study there was a reduction of HbA1c by $1.3 \%$ and FBS by 29.97 $\mathrm{mg} / \mathrm{dl}$ in ranolazine treated patients.

A study done by Selvarajan $\mathrm{S}$, showed that ranolazine when given at $500 \mathrm{mg}$ b.d for 12 weeks had no effect on HbA1c and FBS levels. ${ }^{12}$ Hence it was decided to use $1000 \mathrm{mg}$ b.d in our study.

The mechanism of action (MOA) by which ranolazine reduces HbA1c levels is unclear. Ranolazine as an antianginal drug acts by inhibiting a late $\mathrm{Na}^{+}$current (late $\mathrm{I}_{\mathrm{Na}}$ ) in the myocardium which indirectly facilitates $\mathrm{Ca}^{2+}$ entry through $\mathrm{Na}^{+} / \mathrm{Ca}^{2+}$ exchanger. Reduction in $\mathrm{Ca}^{2+}$ overload in the myocardium during ischaemia decreases contractility and has a cardioprotective effect. ${ }^{13}$

Pancreatic $\alpha$ cells also express voltage gated $\mathrm{Na}^{+}$channels which support the generation of electrical activity and cause an increase in intracellular calcium, leading to exocytosis of glucagon. Ranolazine may exerts its antidiabetic effects by inhibiting glucagon release via blockade of $\mathrm{Na}^{+}$channels in the pancreatic $\alpha$-cells. This MOA is unique in that no other approved antidiabetic drugs acts via this mechanism. ${ }^{14}$ Further studies are required to elucidate the exact mechanism of action.

Diverse nature of background anti diabetic medications is one of the limitations of the study, other being short duration of study. Hence ranolazine may be an effective and well-tolerated anti-anginal medication in diabetic patients with chronic angina since it has an additional antidiabetic action. However, further studies on larger population for longer duration are needed.

Funding: No funding sources Conflict of interest: None declared

Ethical approval: The study was approved by the Institutional Ethics Committee (Ref no.: JJMMC/IEC/Sy06//2015)

\section{REFERENCES}

1. King H, Aubert RE, Herman WH. Global burden of diabetes, 1995-2025: prevalence, numerical estimates, and projections. Diabetes Care. 1998 Sep;21(9):141431.

2. Powers AC. Diabetes mellitus complications. In: Kasper DL. Harrison's principles of internal medicine, 
19th ed. New York: Mc Graw hill education; 2015:2422-2423.

3. Selvin E, Coresh J, Golden SH, Boland LL, Brancati FL, Steffes MW; Atherosclerosis risk in communities study. Glycemic control, atherosclerosis, and risk factors for cardiovascular disease in individuals with diabetes: the atherosclerosis risk in communities study. Diabetes Care. 2005 Aug;28(8):1965-73.

4. Dodani S, Sharma G. Early Screening for coronary artery disease is needed in South Asian Indian immigrants with type 2 diabetes. Endocrinol Metabol Syndrome. 2001;S5:002.

5. Zachariah G, Harikrishnan S, Krishnan MN, Mohanan PP, Sanjay G, Venugopal K, et al. Cardiological Society of India Kerala Chapter Coronary Artery Disease and Its Risk Factors Prevalence (CSI Kerala CRP) Study Investigators. Prevalence of coronary artery disease and coronary risk factors in Kerala, South India: a population survey - design and methods. Indian Heart J. 2013 May-Jun;65(3):243-9.

6. Deshpande DA, Harris M, Schootman M. Epidemiology of diabetes and diabetes related complications. J Am Phy Ther Assoc. 2008;88:125464.

7. Olofsonk E, Cederholm J, Nilsson PM, Zelhelia BJ. New aspects of $\mathrm{HbAlc}$ as a risk factor for cardiovascular disease in type 2 diabetes; Intern med 2010 Nov;268(5):471-82.

8. American Diabetes Association. Standards of medical care in diabetes-2007. Diabetes Care. 2007;30 Suppl $1:$ S4-S41.

9. Mohan V, Venkatraman JV, Pradeepa R. Epidemiology of cardiovascular disease in type 2 diabetes: the Indian scenario. J Diabetes Sci Technol. 2010;4(1):158-70.
10. Chisholm JW, Goldfine AB, Dhalla AK, Braunwald E, Morrow DA, Karwatowska-Prokopczuk E, et al. Effect of ranolazine on $\mathrm{A} 1 \mathrm{C}$ and glucose levels in hyperglycemic patients with non-ST elevation acute coronary syndrome. Diabetes Care. 2010;33(6):11638.

11. Timmis AD, Chaitman BR, Crager M.Effects of ranolazine on exercise tolerance and $\mathrm{HbA1c}$ in patients with chronic angina and diabetes. Eur Heart J. 2006 Jan;27(1):42-8.

12. Sandhiya S, Dkhar SA, Pillai AA, George M, Jayaraman B, Chandrasekaran A. Comparison of ranolazine and trimetazidine on glycemic status in diabetic patients with coronary artery disease-a randomized controlled trial. J Clin Diagn Res. 2015;9(1):OC01-5

13. Chaitman BR, Pepine CJ, Parker JO, Skopal J, Chumakova G, Kuch J, et al. Combination assessment of ranolazine in stable angina investigators. effects of ranolazine with atenolol, amlodipine, or diltiazem on exercise tolerance and angina frequency in patients with severe chronic angina: a randomized controlled trial. JAMA. 2004;291(3):309-16.

14. Dhalla AK, Yang M, Ning Y, Kahlig KM, Krause M, Rajamani S, Belardinelli L;Blockade of $\mathrm{Na}+$ channels in pancreatic $\alpha$-cells has antidiabetic effects. Diabetes. 2014 Oct;63(10):3545-56.

Cite this article as: Shilpa BN, Shashikala GH, Siddesh, Mallesh P. Effect of ranolazine on HbAlc and blood glucose levels in diabetic patients with chronic angina. Int J Basic Clin Pharmacol 2019;8:377-82. 